\title{
Antibodies can be Spontaneously Loaded onto Monosialoganglioside Micelles Containing Oncological Drugs
}

\author{
Ariel G. Garro' ${ }^{1}$, Roxana V. Alasino ${ }^{1,2 *}$, Victoria Leonhard ${ }^{1,2}$, Valeria Heredia ${ }^{1}$ and Dante M. Beltramo ${ }^{1,2,3^{\star}}$ \\ ${ }^{1}$ Centro de Excelencia en Productos y Procesos de Córdoba (CEPROCOR), Córdoba, Argentina \\ ${ }^{2}$ Consejo Nacional de Investigaciones Científicas y Técnicas (CONICET), Argentina \\ ${ }^{3}$ Cátedra de Biotecnología, Facultad de Ciencias Químicas, Universidad Católica de Córdoba, Córdoba, Argentina
}

\begin{abstract}
Recently, we demonstrated that GM1 micelles transport paclitaxel and doxorubicin with high efficiency. When this GM1-drugs complex is incubated with whole serum, albumin was the only one protein that binds spontaneously to form GM1-drug-albumin complex. Here, we show that, under specific physicochemical conditions, these micelles interact with antibodies forming GM1-IgG complexes. The load of IgG in GM1 reaches a maximum at ratios of $1 / 4$ $(\mathrm{w} / \mathrm{w})$ incubating to 4.5 and preheating the micelles of $\mathrm{GM} 1$ at $55-60^{\circ} \mathrm{C}$. The $\operatorname{lgG}$ of the GM1-lgG complex obtained under these experimental conditions retains the biological activity against the soluble and cellular antigens and is not displaced from the micelles in the presence of albumin, the main competitive binding protein.

Treatment of GM1-IgG with pepsin, does not show the breakage of the IgG like control of free $\lg G$, suggesting that IgG is deeply bound into GM1, probably via Fc. Moreover, the presence of $1 \mathrm{M} \mathrm{NaCl}$ does not prevent neither dissociate the complex, suggesting the hydrophobic nature of the interaction. The DLS and TEM results shows that GM1-lgG complexes have sizes significantly higher than those of GM1 micelles; this is directly related to the amount of IgG loaded. On the other hand GM1-IgG complex also retain the ability to encapsulate oncological drugs, but, an adequate sequence must be followed during the preparation, in order to obtain efficient GM1-drug-lgG ternary complexes. Moreover, the presence of IgG into GM1-oncological drugs complex do not affect the release or the citotoxic activity of the encapsulated molecules such as Ptx or Doxo.
\end{abstract}

Keywords: Immunomicelles; Monosialoganglioside (GM1); Targeted drug delivery; Nanomedicine; Cancer

\section{Introduction}

The use of monoclonal antibodies targeting to cell surface antigens on malignant cells, that are generally more numerous on the surface of cancer cells than healthy cells, has positively recognized itself as an effective approach for therapy of solid and hematological tumors. They are designed to function in different ways as flagging cancer cells, triggering cell-membrane destruction, blocking cell growth, preventing blood vessel growth, blocking immune system inhibitors, directly attacking cancer cells, delivering radiation treatment and delivering chemotherapy. Even, one strategy that has received much attention in recent times is the chemistry of attaching antibodies to nanocarriers for targeted cancer therapy to achieve a high degree of selectivity and improve drug absorption or to be used as a dual system. In this sense, numerous procedures have been described for attaching antibodies to carriers and even to drugs for active targeting, including covalent and non-covalent approaches [1-7]. In all cases, the main goal is to bind the antibody without losing its functionality after attachment. One of the most commonly used binding methods is through chemical conjugation using cross-linking reagents. This crosslinking leads to a more stable binding, which could improve the physicochemical stability and halflife of the antibodies and prevent competitive displacement by the blood components. Simultaneously, the incorporation of antibodies into the vehicles carrying the drugs offers clear advantages over the direct conjugation of the antibody into the drug itself $[8,9]$, such as higher drug loading capacity and protection of the drug reaction conjugation. However, these methods often alter the biological functions of antibodies as well as drug transport structures.

Regarding the non-covalent binding of antibodies to the transporters, although methodologically it may be simpler and easier to carry out, there are a number of factors to consider since nonspecific binding has less stability, which can determine the desorption or displacement from antibody by serum proteins which compete for adsorption sites $[1,10,11]$. Similarly, the correct orientation of antibody molecules is a key factor that can reduce or even eliminate the effectiveness of target binding. Therefore, depending on the chosen procedures, it is important to optimize the conditions and characterize the complexes obtained in terms of their physical properties and biological activity.

In previous studies, we describe a self-assembled sialoglycosphingolipid (GM1) micellar system capable of loading and releasing hydrophobic (paclitaxel) and hydrophilic drugs (doxorubicin), or both, with high efficiency $[12,13]$. We also found that GM1 micelles loaded with drugs interact spontaneously with albumin (Human Serum Albumin-HSA) to give GM1-drug-HSA complexes. Here, we demonstrate that subtle specific changes in the conditions that affect both components GM1 and IgG it is possible to obtain the complex of GM1-IgG. We analyze influence of various physical factors in the noncovalent interaction, specially the temperature that modify substantially

${ }^{*}$ Corresponding author: Dante Beltramo, Centro de Excelencia en Productos y Procesos de Córdoba, Pabellón CEPROCOR, CP 5164, Santa María de Punilla, Córdoba, Argentina, Tel: 543541489651/53; Fax: 543541488181; E-mail: dbeltramo@yahoo.com.ar

Roxana Alasino, Centro de Excelencia en Productos y Procesos de Córdoba Pabellón CEPROCOR, CP 5164, Santa María de Punilla, Córdoba, Argentina, Tel: 543541489651/53; Fax: 543541488181; E-mail: v.alasino@gmail.com

Received: April 27, 2019; Accepted: May 13, 2019; Published: May 18, 2019

Citation: Garro AG, Alasino RV, Leonhard V, Heredia V, Beltramo DM (2019) Antibodies can be Spontaneously Loaded onto Monosialoganglioside Micelles Containing Oncological Drugs. J Nanomed Nanotechnol 10: 532. doi: 10.35248/2157-7439.19.10.532

Copyright: (c) 2019 Garro AG, et al. This is an open-access article distributed under the terms of the Creative Commons Attribution License, which permits unrestricted use, distribution, and reproduction in any medium, provided the original author and source are credited. 
the properties of GM1 micelles [14] and the $\mathrm{pH}[15,16]$ to optimize amount of $\mathrm{mAb}$ bound to the micelles, its stability, biological activity and the capability to load oncological drugs.

\section{Materials and Methods}

\section{Materials}

GM1 was supplied by TRB Pharma S.A. Total human IgG antibodies were provided by Laboratory of Hemoderivados, National University of Córdoba (Córdoba, Argentina). Rubella IgG antibodies were measured using Immulite / Immulite 1000 analyzer and antiHBs were analyzed using Roche Elecsys immunoassay analyzer. Monoclonal antibodies CD4-FITC / CD8-PE / CD3-PC5 (OptiClone) were from Immunotech, Beckman, France. Anti-HER-2/neu (4B5) rabbit monoclonal primary antibody and anti-Ki-67 primary rabbit monoclonal antibody (IgG) directed against C-terminal portion of Ki-67 antigen were from Ventana Medical Systems, Inc., USA. AntiFR IgG primary antibodies (folate receptor-targeted antibody), antiLDLR IgG (anti-LDL receptor targeted antibody) and anti-CD44 IgG (antibody targeted against the receptor for hyaluronic acid) were purchased from Sigma Aldrich. Paclitaxel (Ptx) was acquired from Yunnan Smandbet Co. Ltd. (Kumming, China). The stock solutions of Ptx were prepared by dissolving the drug in dimethylsulfoxide (DMSO) at a final concentration of $50 \mathrm{mg} \mathrm{mL}-1$. Doxorubicin (Doxo) was obtained from Sigma. Stock solutions of Doxo were prepared in physiologic solution at $6 \mathrm{mg} \mathrm{mL}^{-1}$. Sephadex G-25 and G200 columns were purchased from GE Healthcare (Buckinghamshire, UK). All other reagents were of analytical grade, used as received from Merck (Darmstadt, Germany).

\section{Methods}

Cell lines cultures: The following continuous cell lines were used: human cervical epithelioma cells (HeLa), non-small cell human lung carcinoma cells (H1299) and highly metastatic mouse melanoma cells (B16).

For cell cultures, MEM for HeLa and DMEM-F12 for H1299 and B16 cells, were supplemented with irradiated fetal calf serum (NATOCOR, Córdoba, Argentina) at 1 or $10 \%(\mathrm{v} / \mathrm{v})$ according to maintenance or growth conditions, respectively.

Preparation of IgG antibodies coupled to GM1 micelles: Stock solution of $250 \mathrm{mg} \cdot \mathrm{ml}^{-1} \mathrm{GM} 1$ was prepared in bidistilled water $24 \mathrm{~h}$ prior to use. The solutions were maintained at $4-8^{\circ} \mathrm{C}$ for $24 \mathrm{~h}$ and centrifuged at $50,000 \mathrm{~g}$ for $15 \mathrm{~min}$. The supernatant was finally filtered through 0.22 $\mu \mathrm{m}$. The micelles (GM1) were then incubated with human IgG under different conditions of pHs ( $3,4.5$ and 7.4), temperatures $(4,25,37,45$ and $55^{\circ} \mathrm{C}$ ) and times (from 2 to $24 \mathrm{~h}$ ).

The results of these assays were analyzed by chromatographic analysis.

Size exclusion chromatography (SEC): The GM1-IgG complexes were isolated and quantified by size exclusion chromatography. Samples and controls were run on an Åkta Explorer 100 system (GE Healthcare) fitted with a Superdex 200 column, previously equilibrated with $50 \mathrm{mM}$ phosphate buffer ( $\mathrm{pH} 7.4$ ) and $150 \mathrm{mM} \mathrm{NaCl}$ at a rate of $0.4 \mathrm{~mL} \mathrm{~min}^{-1}$. The elution profile was followed using a UV-visible detector at 200 and $280 \mathrm{~nm}$ for GM1 micelles and protein respectively [17].

Native SDS-PAGE analysis: The identification of antibodies after incorporation into the micelles and eluted by size exclusion chromatography was detected by SDS-PAGE and compared with the native antibody control. The gels were run under native conditions (without 2-mercaptoethanol) using a BioRad Mini-Protean II kit at a constant voltage of $200 \mathrm{~V}$ in Tris/glycine/SDS buffer. The gels were stained with Coomassie blue.

Determination of IgG concentration: IgG concentration was determined using a Lowry assay [18] or by direct absorbance at $280 \mathrm{~nm}$.

Digestion of IgG incorporated in GM1 micelles with pepsin: $20 \mu \mathrm{l}$ $(0,4 \mathrm{mg})$ of pepsin under acid conditions was added to $1 \mathrm{ml}$ of GM1IgG complex $(5 / 1 \mathrm{w} / \mathrm{w})$ previously prepared. The mixture was incubated at $37^{\circ} \mathrm{C}$ in buffer $\mathrm{pH} 4.5$ in a shaking water bath and $20 \mu \mathrm{l}$ aliquots were taken at $30 \mathrm{~min}$ for IgG control and at 15, 30, 60 and 90 min for GM1IgG for analysis by gel electrophoresis.

Particle size and size distribution: Average particle size and size distribution of the nanoparticles were measured by laser light scattering (LLS, Delsa TM Nano, Beckman Coulter Instruments). The samples were diluted with PBS buffer $\mathrm{pH} 7.4$ and filtered before measurement. Data were analyzed using Delsa ${ }^{\mathrm{T}}$ Nano Beckman Coulter software (version 2.2). All measurements were done in triplicate, for each of three micelle-independent batches.

Surface charge: The zeta potential of the GM1-IgG complexes was determined using a Delsa TM Nano zeta potential analyzer (Beckman Coulter Instruments) at room temperature. The samples were prepared by diluting the micelle solutions with PBS buffer $\mathrm{pH}$ 7.4. Particle sizes of the micelles were measured to assure that micellar structure was intact. Samples were diluted with PBS buffer (145 mM NaCl) pH 7.4 and filtered prior to measurement. The zeta potential was determined in triplicate and results were calculated automatically by the analyzer.

Transmission electron microscopy (TEM): A JEOL JEM-1200 EX II transmission electron microscope was used at $300000 \mathrm{X}$ to establish the morphology of the modified micelles. $50 \mu \mathrm{l}$ of each sample was loaded onto a carbon grid, incubated for $5 \mathrm{~min}$ and the grid was then dried. The gratings were then incubated with $50 \mu \mathrm{l}$ of a $10 \%$ uranyl acetate solution for $1 \mathrm{~min}$, dried and taken under a microscope for observation.

Drug encapsulation and loading efficiency: To assess whether IgG binding to GM1 micelles affects the loading capacity of the micelle, we evaluated the load of increasing amounts of Ptx or Doxo in GM1-IgG micelles of $10 \mathrm{mg} \cdot \mathrm{mL}^{-1}$ to reach micelle/drug molar ratios from 50/1 to $1 / 1$. Drug loading was performed at $20^{\circ} \mathrm{C}$ for $30 \mathrm{~min}$ before incubating the samples at $4^{\circ} \mathrm{C}$ for $24 \mathrm{~h}$. After incubation time, the samples were dialyzed against PBS buffer $\mathrm{pH} 7.4$ for $24 \mathrm{~h}$ at $4^{\circ} \mathrm{C}$ to remove the free drugs. In addition, the influence of the loading order of the drug and IgG was analyzed.

Determination of Ptx concentration: Ptx concentration was measured on a Curosil B C18 column $(250 \times 3.20 \mathrm{~mm}$ I.D., particle size $5 \mu \mathrm{m})$ and a Curosil BC18 guard column $(30 \times 4.60 \mathrm{~mm}$ I.D., particle size $5 \mu \mathrm{m}$ ) supplied by Phenomenex as we previously described [11]. The mobile phase was $60 \%(\mathrm{v} / \mathrm{v})$ acetonitrile and $40 \%(\mathrm{v} / \mathrm{v})$ bidistilled

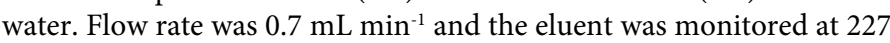
$\mathrm{nm}$. Chromatography was performed at ambient temperature $\left(20^{\circ} \mathrm{C}\right)$. Validation of the method was carried out according to FDA Guidance for Bioanalytical Method Validation.

Determination of doxo concentration: Doxo concentration was determined by absorbance at $490 \mathrm{~nm}$ using a calibration curve performed with a standard solution of Doxo in physiologic solution, as described by Abraham et al. [19]. 
Recognition properties of antibodies bound to GM1 micelles: The following methods were used to evaluate the functionality of the $\mathrm{mAb}$ on the micelle surface.

Flow cytometry: A combination of three anti-CD4-FITC / CD8PE / CD3-PC5 (OptiClone) fluorescent monoclonal antibodies, previously absorbed on the micelles and eluted through a size exclusion column (Sephadex G- 200) was incubated with a whole blood sample. After incubation, the red blood cells were lysed using a non-washed procedure, the processed sample was then directly introduced into the flow cytometer for analysis. After excitation at $488 \mathrm{~nm}$, each fluorescent marker emitted light at different wavelengths, allowing the simultaneous study of CD4, CD8 and CD3 antigens, respectively. The use of dispersion diagrams (representation of lateral dispersion vs. frontal dispersion) allows discrimination of lymphocytes waste, monocytes and polymorphonuclear cells.

\section{As controls, free antibodies and uncoated micelles were analyzed.}

Chemiluminescent immunoassay: A solid-phase, sequential chemiluminescent immunoassay IMMULITE/IMMULITE 1000 Rubella Quantitative IgG for in vitro diagnostics was performed to determine the functionality of the anti-Rub IgG antibodies absorbed on GM1 micelles. First, anti-Rub IgG antibodies were absorbed at the experimental conditions selected. Samples were then eluted by a size exclusion column to remove free antibodies. Finally, their biological activity was measured and compared with standard anti-Rub IgG antibodies. Likewise, anti-HBs IgG antibodies were absorbed into GM1 micelles and eluted through a size exclusion column to separate the free antibodies. Subsequently, their biological activity with standard antiHBs IgG antibodies was measured and compared by a sandwich-type chemiluminescent immunoassay against hepatitis B surface antigen (HBsAg).

Immunohistochemistry: Anti-HER-2/neu and rabbit anti-Ki-67 IgG primary monoclonal antibodies were absorbed into GM1 micelles, under pre-established experimental conditions and then incubated with tumor tissue sections, which express the specific antigen, fixed in formalin for 16 to $32 \mathrm{~min}$. Finally, the tissues with the samples were stained on a slide, with the detection kit provided by Ventana.

The ability of antibodies to recognize their specific antigen after being absorbed into the micelles was compared to that of the same free antibodies using images obtained by optical microscopy of consecutive tissue sections.

In vitro interaction assays of GM1-antibody complexes with cells expressing specific receptors: Different specific antibodies, anti-FR, anti-CD44, anti-HER-2/neu and anti-LDLR, were used to evaluate the surface expression of specific receptors in the different cell lines mentioned above. In parallel, cells were incubated with the same antibodies adsorbed into GM1 micelles to evaluate the specific interaction of GM1-anti receptor IgG with the cells. Briefly, confluent monolayers were incubated with the different anti-receptor antibodies, at concentrations between 1 and $20 \mu \mathrm{g} \cdot \mathrm{ml}^{-1}$ and 4 to $24 \mathrm{~h}$ at $37^{\circ} \mathrm{C}$. After incubation, cells were washed extensively with PBS to remove unreacted material and a Peroxidase enzyme-labeled anti-IgG secondary antibody was added at different dilutions for $2 \mathrm{~h}$ at $37^{\circ} \mathrm{C}$. Finally, the monolayers were washed again to remove the unreacted labeled anti-antibodies and the bound material was analyzed by colorimetric spectrophotometry. The final colorimetric evaluation was performed after the addition of a specific substrate (chromogenic), the ortophenylenediamine (OPD), on which the peroxidase enzyme acts and gives an observable and quantifiable colored reaction product. Absorbance measurements were performed on an automated plate reader (BioRad., CA, USA) at $\lambda=490 \mathrm{~nm}$. The reaction blank for the absorbance of each sample was discounted. The untreated monolayers to which only the labeled secondary antibody and the chromogen were added for the reaction were taken as reaction blank. The results represent mean values of three measurements and their respective deviations.

In vitro cytotoxicity of Paclitaxel or doxorubicin loaded in GM1drug-antibody complexes: Cytotoxicity assays were performed using the cell lines which exhibited the expression of specific receptors $(+)$, such as: non-small cell human lung carcinoma cells (H1299)-CD44(+); highly metastatic mouse melanoma cells $(\mathrm{B} 16)-\mathrm{FR}(+)$ and $\operatorname{LDLR}(+)$; and human cervical epithelial cells (HeLa)-CD44(+).

Confluent monolayers grown in 96 well plates were incubated with GM1-Doxo or GM1- Doxo- IgG micelles with different Doxo final concentrations $\left(10,25,50 \mu \mathrm{g} \cdot \mathrm{ml}^{-1}\right)$ at different times $(30 \mathrm{~min}$ to $8 \mathrm{~h}$ ). After each time, the medium with the sample was replaced by fresh medium and incubated $24 \mathrm{~h}$ at $37^{\circ} \mathrm{C}$ and $5 \% \mathrm{CO}_{2}$. After $24 \mathrm{~h}$ the cells were washed three times with PBS, fixed with $10 \%$ formaldehyde and then stained with a solution of $0.4 \%$ crystal violet in methanol, widely used to evaluate the cytotoxic activity of drugs or biomaterials. Subsequently a solution of $5 \%$ acetic acid was added to the stained cells to dissolve the color after 10-15 min absorbance was determined.

Quantitative analysis (colorimetric assay of the fixed cells) was performed by absorbance measurements on an automated plate reader (Bio-Rad., CA, USA) at $620 \mathrm{~nm}$. Cell viability was calculated and compared between samples. Untreated cells incubated with culture medium only were taken as negative control, $100 \%$ cell survival The results represent mean values of three measurements and their respective deviations.

The assays with Ptx were performed in a similar way to those of Doxo; cells monolayers were incubated with Ptx, GM1-Ptx or GM1Ptx- anti receptor IgG for $24 \mathrm{~h}$ and results were quantitatively analyzed by crystal violet assay.

\section{Results}

\section{Characterization of the interaction of IgG antibodies with GM1 micelles}

Previously, we described that GM1 micelles interact spontaneously with albumin, but not with immunoglobulins. In this work, we evaluated if modifying properties of GM1 or IgG under different experimental conditions allow achieving the interaction between micelles and antibodies. To do this, we begin evaluating whether the modification of the structure of IgG by changes in $\mathrm{pH}$, in a range of 4.5 to 7.5 , leads to interaction. The interaction was evaluated by size exclusion chromatography. Considering that pure GM1 micelles $(\sim 375 \mathrm{kDa})$ eluted with the $\mathrm{V}_{0}$ (unretained fraction) of the column (data not shown) and IgG fraction $(150 \mathrm{kDa})$ eluted in the fraction corresponding to a volume about $6 \mathrm{ml}$. When GM1 micelles $\left(20 \mathrm{mg} \cdot \mathrm{ml}^{-1}\right.$ ) were incubated with $\operatorname{IgG}\left(5 \mathrm{mg} \cdot \mathrm{ml}^{-1}\right)$ at $25^{\circ} \mathrm{C}$ at $\mathrm{pH} 7.4$ and eluted at pH 7.4 each component kept its original profile with only less that $5 \%$ of the added immunoglobulin interacts with micelles confirming that no association occurs under this $\mathrm{pH}$ condition (Figure 1A). However, when GM1 micelles $\left(20 \mathrm{mg} \cdot \mathrm{ml}^{-1}\right)$ were incubated with IgG $\left(5 \mathrm{mg} \cdot \mathrm{ml}^{-1}\right)$ and eluted at $\mathrm{pH} 4.5$, a condition that produces changes in the $\mathrm{Fc}$ by exposure of hydrophobic components but it does not affect IgG activity nor GM1 structure, the elution profile showed a shift to a unique high molecular weight specie ( $\geq 375 \mathrm{kDa}$ ) where practically all the IgG elutes with the GM1 micelles, demonstrating a physical association between 
these two fractions. On the other hand, when the incubation is carried out at $\mathrm{pH} 4.5$ and then eluted at $\mathrm{pH} 7$, the appearance of a second peak of $150 \mathrm{kDa}$, corresponding to the $\mathrm{IgG}$, indicate a partial dissociation of the complex.

Considering the reversible conformational denaturation of the IgG at acidic $\mathrm{pH}$, with the consequent exposure of hydrophobic residues, mainly in the Fc region $[15,16]$, our results about the binding of IgG to GM1 micelles at $\mathrm{pH} 4.5$ suggest an interaction of hydrophobic nature. To better understand the nature of the GM1-IgG interaction at $\mathrm{pH} 4.5$, we added $1 \mathrm{M} \mathrm{NaCl}$ to dissociate a possible electrostatic interaction of the complex, which did not happen, reinforcing the concept of the hydrophobic nature of the interaction.

To evaluate the effect of temperature on GM1-IgG interaction, we incubate the complex in two different experimental conditions and then molecular exclusion chromatography was also used. First one, increasing the incubation temperature in a range from $4^{\circ} \mathrm{C}$ until to $45^{\circ} \mathrm{C}$, the maximum temperature that not affect the biological activity of IgG. Figure $1 \mathrm{~B}$ show that the binding of the immunoglobulins to the GM1 micelles increase around from $4-5$ times from $4^{\circ} \mathrm{C}$ to $45^{\circ} \mathrm{C}$.

The second one is an assay where the temperature affects only the $\mathrm{GM} 1$ micelles. It has been reported that temperatures above $55^{\circ} \mathrm{C}$ induce the release of water molecules bound to the oligosaccharide chain of gangliosides, resulting in a significant reduction of the hydrophilic portion, accompanied by a slight extension of the hydrophobic region of the micelles $[20,21]$. When GM1 micelles were preheated at $55^{\circ} \mathrm{C}$
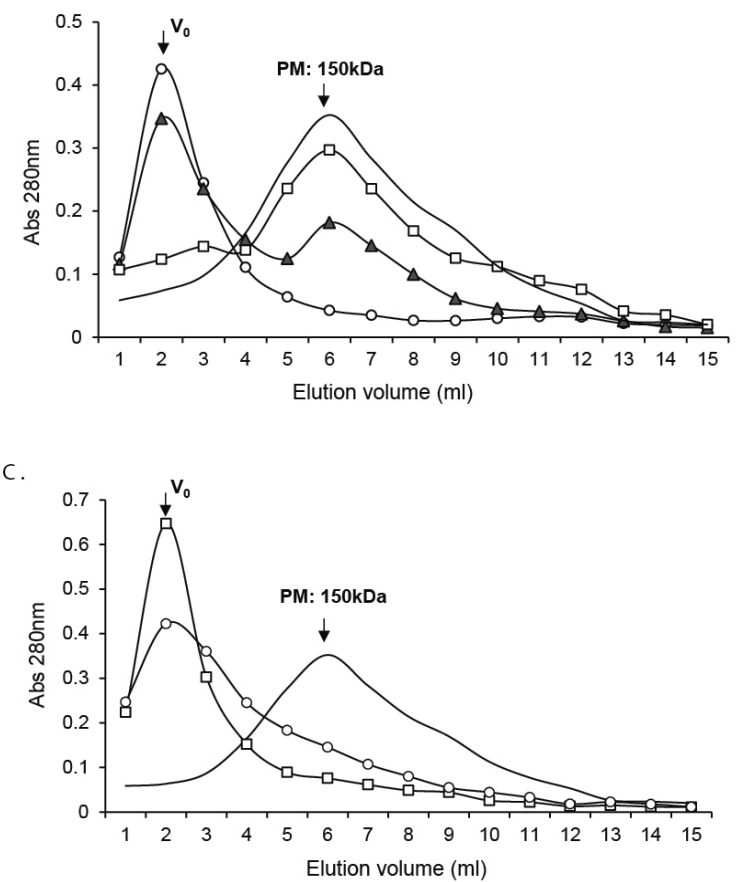

for $30 \mathrm{~min}$ at $\mathrm{pH} 4.5$ and then stabilized at room temperature, the binding of IgG to this GM1 was higher than that for GM1-IgG complex heated together at $45^{\circ} \mathrm{C}$ described above (Figure 1C). These results, demonstrate that temperature and especially those that affect the GM1 play a key role in the interaction.

A common disadvantage of the physical adsorption of antibodies to nanocarriers is the competitive displacement by blood components $[1,10,11]$. Considering the spontaneous association of albumin (HSA) with GM1, demonstrated in previous reports of our own and other authors $[12,17,22,23]$, we analyzed whether the presence of albumin affects the interaction of immunoglobulins with GM1 micelles.

To evaluate this, GM1 micelles $\left(20 \mathrm{mg} \cdot \mathrm{ml}^{-1}\right)$ at $\mathrm{pH} 4.5$ were incubated during $30 \mathrm{~min}$ at $45^{\circ} \mathrm{C}$ with a solution containing both IgG ( $5 \mathrm{mg} \cdot \mathrm{ml}^{-1}$ ) with increasing concentrations HSA from 0 to $8.8 \mathrm{mg} / \mathrm{ml}$ and then the elution profile of proteins was analyzed. Figure $2 \mathrm{~A}$ shows that the presence of increasing amounts of HSA (from 0 to $8.8 \mathrm{mg} \cdot \mathrm{ml}^{-1}$ ) induced the appearance of a new peak which correlates with the elution pattern of IgG $(150 \mathrm{kDa})$ that increases with albumin concentration. These results demonstrate that, under this experimental condition, there is a competitive binding site for both proteins in GM1 micelles. Figure 2B shows the SDS-PAGE analysis of fractions eluted from the size exclusion column. With $2.2 \mathrm{mg} \cdot \mathrm{ml}^{-1} \mathrm{HSA}$ (Figure 2B- SDS-PAGE a), both proteins HSA and IgG appear to be bound to GM1 micelles and elute together in the column as can be seen in the same fractions of SDS-PAGE, whereas in presence of HSA 4.4 and $8.8 \mathrm{mg}^{-\mathrm{ml}^{-1}}$ (2BSDS-PAGE b) and (2B-SDS-PAGE c), only HSA can be seen in the

B.

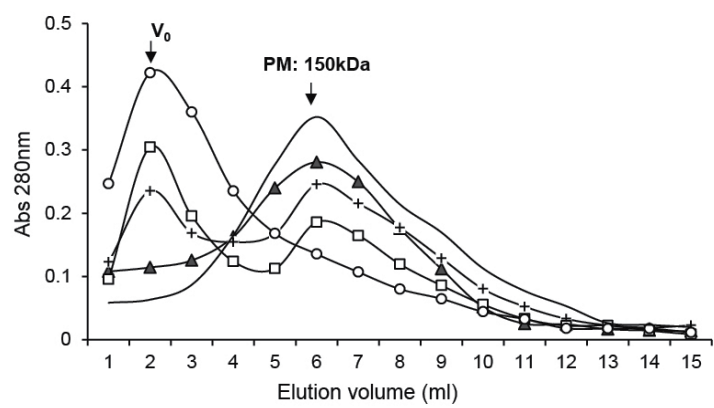

Figure 1: A- Pattern of chromatographic elution on Superdex $200 \circledast$ of $\operatorname{lgG}$ binding to $\mathrm{GM} 1$ at different pH: $\operatorname{lgG}$ control at pH 7.4 (- ), GM1 and IgG incubated and eluted $\mathrm{pH} 4.5$ ( $\circ$ ); GM1 and IgG incubated pH 4.5 and eluted $\mathrm{pH} 7.4$ ( $\mathbf{\Delta}$ ) and GM1 and IgG incubated and eluted at $\mathrm{pH} 7.4(\gamma)$. B- Pattern of chromatographic elution on Superdex $200 \otimes$ of IgG binding to GM1 at different temperatures. Samples of GM1 and lgG at pH 4.5 were incubated at temperatures indicated below for 30 min and then the elution was done at $25^{\circ} \mathrm{C}$. IgG control $(-), \mathrm{GM} 1$ and $\operatorname{lgG}$ at: $4^{\circ} \mathrm{C}(\boldsymbol{\Delta}) ; 25^{\circ} \mathrm{C}(+) ; 37^{\circ} \mathrm{C}(\gamma)$ and $45^{\circ} \mathrm{C}(\not \subset)$. C - Pattern of chromatographic elution on Superdex $200 \AA$ of $\operatorname{lgG}$ binding to pre-heated $\mathrm{GM} 1$ at $55^{\circ} \mathrm{C}$ and then allowed to reach $25^{\circ} \mathrm{C}$ and incubated with $\operatorname{lgG}(\gamma)$; IgG and $\mathrm{GM} 1$ incubated at $45^{\circ} \mathrm{C}$ and eluted $25^{\circ} \mathrm{C}(\not \subset)$ and IgG control (- ). All samples were run at $\mathrm{pH} 4.5$. 


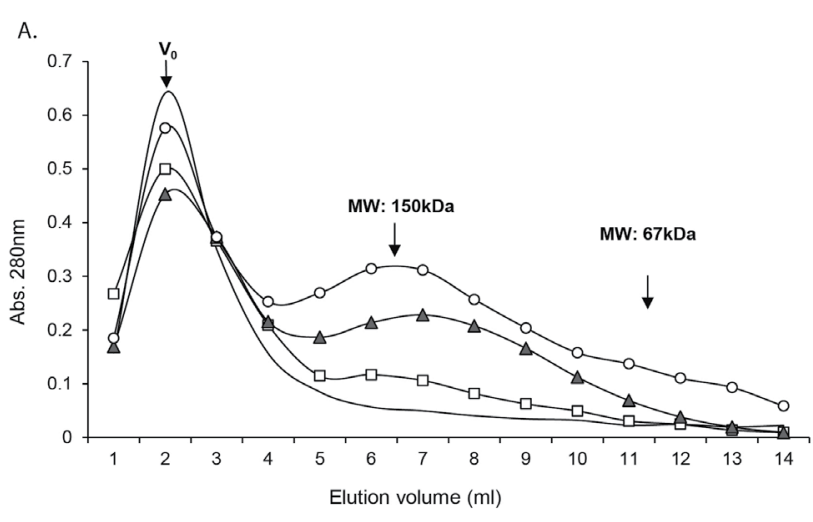

B.

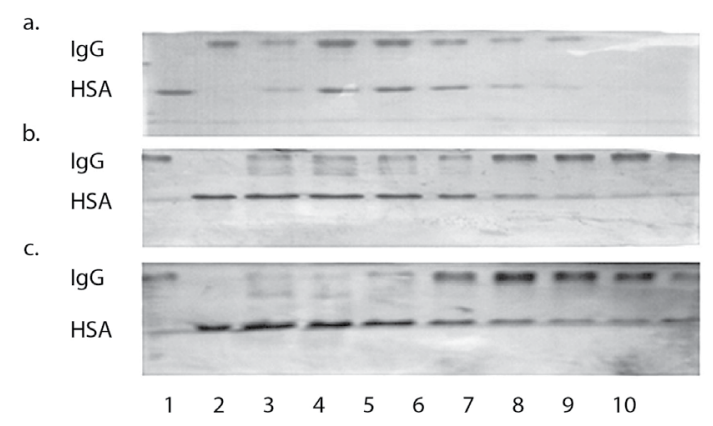

Figure 2: Patterns of size-exclusion chromatographic GM1-lgG complex (20 mg. $\mathrm{ml}^{-1} \mathrm{GM} 1$ and $5 \mathrm{mg} \cdot \mathrm{ml}^{-1} \mathrm{lgG}$ ) incubated with increasing concentration of $\mathrm{HSA}$ at $\mathrm{pH}$ 4.5. A- Chromatography on Superdex $200 \circledast$ of GM1-lgG, GM1-lgG with $2.2 \mathrm{mg}^{-1} \mathrm{ml}^{-1}$ of HSA (口), GM1-lgG with $4.4 \mathrm{mg}^{-1} \mathrm{ml}^{-1}$ of HSA $(\boldsymbol{\Delta})$ and GM1IgG with $8.8 \mathrm{mg}^{\mathrm{ml}} \mathrm{l}^{-1}(\circ)$ of HSA. B- Native SDS-PAGE of elution fractions of size-exclusion chromatographic of GM1-lgG complex incubated with different amounts of HSA at pH 4.5. Lanes 1-2: IgG and HSA standards; Lanes 3-10: profile elution of: a: GM1-IgG micelles with $2.2 \mathrm{mg}^{-1} \mathrm{ml}^{-1} \mathrm{HSA}$; b: GM1-lgG micelles with $4.4 \mathrm{mg}^{\mathrm{ml}}{ }^{-1} \mathrm{HSA}$ and $\mathrm{c}$ : $\mathrm{GM} 1-\mathrm{lgG}$ micelles with $8.8 \mathrm{mg}^{-\mathrm{ml}^{-1}} \mathrm{HSA}$.

initial fractions of SDS-PAGE while IgG appear in retarded fraction corresponding with MW $150 \mathrm{kDa}$, confirming the results described above.

Interestingly, when the complex of GM1-IgG is obtained at $\mathrm{pH}$ 4.5 and then adjusted to $\mathrm{pH} 7.4$, the addition of HSA at 4,4 and 8,8 mg. $\mathrm{ml}^{-1}$ was not able to displaced the IgG such as describe above when both proteins were co incubated at same time since the complex GM1IgG eluted in $V_{0}$, suggesting that under physiological conditions IgG would remain attached to the micelles.

As mentioned above, the binding of IgG to micelles is optimal after preincubating GM1 micelles at $55^{\circ} \mathrm{C}$ and allowed to reach room temperature before incubating with IgG at $\mathrm{pH}$ 4.5. Using this experimental condition, we evaluated the maximum binding capacity of IgG to a fixed concentration of GM1 micelles. The result revealed that GM1 reaches its maximum capability to bind IgG at GM1/IgG ratio $4 / 1 \mathrm{w} / \mathrm{w}$ (data not shown). Considering the apparent $\mathrm{MW}$ of the GM1 micelles which, when heated to $55^{\circ} \mathrm{C}$, is $320 \mathrm{kDa}[20,21]$ and the MW of the IgG, of $150 \mathrm{kDa}$, the complex would be formed by two antibody units per micelle of GM1.

\section{Physicochemical characterization of GM1-IgG micelles}

Here we characterize the physicochemical properties of these mixed micelles. Studies about particle diameter, polydispersity index, surface morphology and $\mathrm{z}$ potential were assessed. Table 1 shows the results of these studies of GM1-IgG in comparison with free GM1 micelles. The GM1-IgG micelles had a mean diameter in the range of $25.0 \mathrm{~nm}$, while GM1 micelles shows only $11.9 \mathrm{~nm}$, which shows that the presence of IgG on micellar surface increased the size about $100 \%$. The polydispersity of different composition of GM1-IgG micelles (10/1 and 4/1 GM1/IgG weight /weight ratio) were very similar but with relatively high values of about $0.28 \pm 0.09$, however this result does not appear to be related to the amount of IgG on the surface. On the other hands, using transmission electron microscopy we also can visualize this size changes. The images of Figure $3 \mathrm{~A}$ shows the particle size of GM1 micelles and in Figure 3B the changes observed in the GM1/IgG $4 / 1$ weight /weight ratio that also show a longer dispersion interval.

Next we evaluate whether the presence of IgG in the surface of GM1 micelles induce changes on surface charge of final structure. Table 1 shows that the zeta potential values obtained for GM1-IgG in proportions of $10 / 1$ and $4 / 1 \mathrm{w} / \mathrm{w}$, were $-10.6 \pm 0.3$ and $-11.8 \pm 1.2$ respectively and $-8.1 \pm 1.0$ for the micelles of GM1 alone. These results seems to indicate no substantial changes in zeta potential after the insertion of a high molecular weight protein like IgG into micelles, however, taking into account that GM1-IgG micelles were prepared from GM1 micelles preheated to $55{ }^{\circ} \mathrm{C}$, that show a zeta potential of $-23.6 \pm 1.9$, the zeta potential values of the complex would indicate a substantial molecular reorganization according to these results.

\section{Topology of the IgG in the micellar structure}

After demonstration of GM1-IgG interaction and the characterization of the physicochemical properties, we inquired about the final orientation of immunoglobulin in the micelle structure. To do this, we performed a proteolityc assay with pepsin, an enzyme which specifically cuts IgG separating Fab region from fragments of low molecular weight of Fc.

The results shows that pepsin on free IgG it produces the release of Fab fragment, however, under similar condition very little or none IgG was cleaved by pepsin from GM1-IgG complex, which suggest that the immunoglobulin would be bound to the micelle by the Fc region of the molecule, keeping the specific recognition of IgG (Figure 4).

Table 1: Physicochemical characteristics of GM1 micelles and GM1-IgG modified micelles.

\begin{tabular}{|c|c|c|c|c|c|}
\hline \multirow{4}{*}{ Parameters } & \multicolumn{5}{|c|}{ Samples } \\
\hline & \multirow{3}{*}{$\lg G$} & \multirow{3}{*}{$\mathrm{GM}_{1}$} & GM & 1-Oct & 1-Apr \\
\hline & & & (heated $55^{\circ} \mathrm{C}$ ) & $\mathbf{G M}_{1} / \mathbf{I g G}$ & $\mathbf{G M}_{1} / \mathbf{l g G}$ \\
\hline & & & & w/w ratio & w/w ratio \\
\hline MD (nm) & $6.4 \pm 2$ & $14.2 \pm 3$ & $11.9 \pm 2$ & $20.8 \pm 2$ & $25.1 \pm 2$ \\
\hline PI & $0.16 \pm 0.06$ & $0.17 \pm 0.08$ & $0.11 \pm 0.03$ & $0.28 \pm 0.09$ & $0.28 \pm 0.08$ \\
\hline$z(m V)$ & $-7.8 \pm 1.1$ & $-8.1 \pm 1.0$ & $-23.6 \pm 1.9$ & $-10.6 \pm 0.3$ & $-11.8 \pm 1.2$ \\
\hline
\end{tabular}
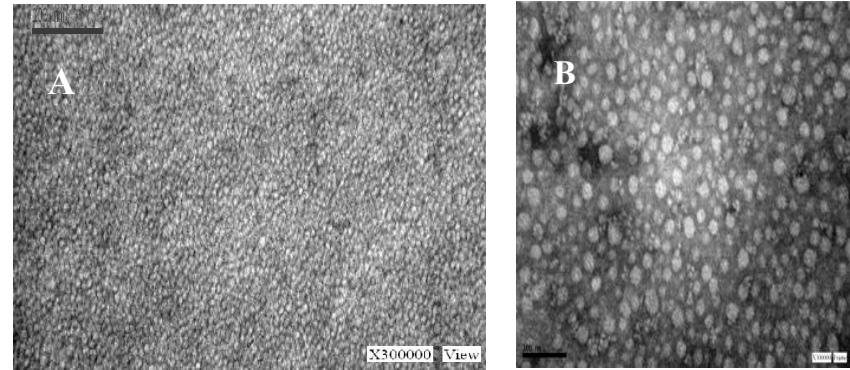

Figure 3: Electron micrography of $\mathrm{GM} 1$ heated at $55^{\circ} \mathrm{C}(\mathrm{A})$ and $\mathrm{GM} 1-\mathrm{IgG}$ mixed micelles (B). X300000. Size bar: $100 \mathrm{~nm}$. 
Citation: Garro AG, Alasino RV, Leonhard V, Heredia V, Beltramo DM (2019) Antibodies can be Spontaneously Loaded onto Monosialoganglioside Micelles Containing Oncological Drugs. J Nanomed Nanotechnol 10: 532. doi: 10.35248/2157-7439.19.10.532

Page 6 of 10

\section{Biological activity of antibodies associated with micelle surface}

Here we evaluate whether the IgG incorporated in the GM1 micelles retain the biological activity by measurement the capability to recognize three different antigen species such as 1- soluble antigens, 2-cell surface antigens and 3- antigen expressed in sections of human tumor tissues.

For the first example, to analyze the recognition of soluble antigen, we used an anti-Rub IgG from a commercial kit of rubella virus adsorbed to the GM1 micelle. The biological activity of the antibody was determined by a chemiluminescence enzyme immunoassay. Table 2 shows that the purified complex of GM1-anti-Rubella virus antibodies retains their specific recognition ability against soluble antigens with a similar activity than control of anti-Rubella virus antibodies. Moreover, it was also observed a direct quantitative relationship between the biological activity and the amount of antibody adsorbed on the micelle. Nonspecific IgG antibodies bound to GM1 micelles were used as controls to rule out non-specific binding.

To evaluate the activity of GM1-antibodies against antigens located in the cellular surface we used a combination of three fluorescent monoclonal antibodies, anti-CD4-FITC /CD8-PE /CD3-PC5 (OptiClone), which were loaded onto GM1 and purified as GM1-IgG as mentioned before. The mixture was incubated with whole blood samples, after which red blood cells were lysed using a no-wash assay and finally the samples were analyzed by flow cytometry. The results indicate that the loaded of the immunoglobulins to the micelles does not affect their specific recognition property against antigens expressed in cells in suspension (Table 3).

On the hand the interaction of the GM1-antibodies with another class of cell surface antigen such as receptor were also evaluated. The specific receptors expressed on the cell surface was evaluated using antiFR IgG, anti-CD44 IgG and anti-LDLR antibodies, which were absorbed to GM1 micelles and analyzed by colorimetric spectrophotometry. The results reveal no significant differences between the antibodies loaded to the micelles compared to the controls (Table 4). GM1 micelles alone and loaded with total human IgG were used as controls to confirm absence of nonspecific binding. All these results seem to prove that the incorporation of the antibodies into the micellar structure does not affect their functionality.

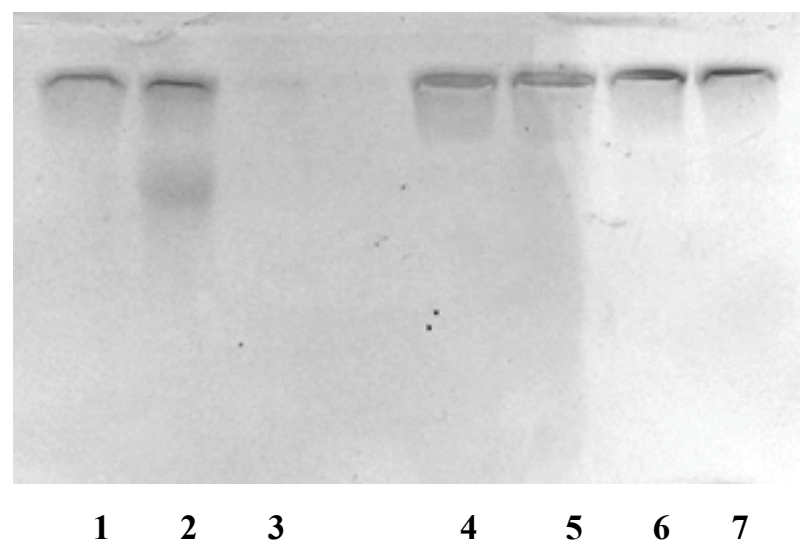

Figure 4: Treatment of free IgG and IgG loaded on GM1 micelles with pepsin. Samples of free $\operatorname{lgG}$ and $\mathrm{GM} 1-\mathrm{lgG}$ at $\mathrm{pH} 4,5$ were incubated at room temperature for different times with pepsin and then subjected to SDS-PAGE in non denaturating conditions. Lane 1: IgG control; Lane 2: IgG treated $30 \mathrm{~min}$ with pepsin; Lane 3: Pepsin control; lines 4-7: GM1-lgG treated with pepsin at different times: 15, 30, 60, $90 \mathrm{~min}$.
Finally we also studied the activity of anti-Her2 or anti-KI67 antibodies loaded in GM1 micelles by immune-histochemistry (IHC) to evaluate recognition of specific antigen expressed in sections of human tumor tissues. Immuno histochemical visualization of the antigenantibody complex was performed by staining with a fluorochrome or enzyme, depending on the labeling of the antibody. Figure 5 shows that the GM1-antibodies are able to recognize their specific antigens on tissues, in this case the epidermal growth factor and the nuclear protein KI-67 in similar extension that control of free antibodies.

\section{Effect of IgG in GM1 micelles on drugs encapsulation, release and cytotoxic activity of drugs}

In previous reports we demonstrate that GM1 micelles were able to load hydrophobic or hydrophilic drugs such Ptx, Dtx, Doxo and AmB $[12-13,17]$. Here we evaluate capability of this GM1-IgG complex to discern whether this modification affects their drug loading capacity, drug release or the pharmacological activity.

We found that increasing the amount of IgG in the GM1-IgG complex produce a decreased in the amount of hydrophobic drug Ptx loaded in GM1-IgG micelles, Table 5 However, when the incorporation of the Ptx on GM1 occurs before the binding to IgG, the efficiency of Ptx encapsulation remain similar to that described above for pure GM1 micelles [12]. These results suggest that IgG could be located in external domains of GM1 micelles, which prevents subsequent entry of Ptx in the hydrophobic region of the micelles. By other hands, suggest that Ptx could be located deeply in the GM1 micelles as was proposed in previous report [12] a condition that not affect the binding of de IgG to GM1 micelles to form finally the GM1-Ptx-IgG complex.

The loaded of water soluble drug Doxorubicine into GM1-IgG micelles is substantially affected by the presence of IgG. At the GM1/ IgG $(4 / 1 \mathrm{w} / \mathrm{w}$ ratio) the saturating condition, the amount of Doxo that can be incorporated decreases four times with respect to its optimum capability to be loaded in free GM1 micelles (at molar ratio 5/1 GM1/Doxo). In this case, unlike what happens with Ptx, the load of increasing concentrations of Doxo into free GM1 micelles before adding IgG, produce a significantly decrease in the amount of IgG

Table 2: Test IMMULITE 1000. Quantitative measurement of IgG antibodies to rubella virus. Solid-phase, sequential chemiluminescent immunoassay for in vitro diagnostic use.

\begin{tabular}{|c|c|}
\hline \multicolumn{1}{|c|}{ Sample } & $\begin{array}{c}\text { Biological Activity } \\
\text { mUl/ml }\end{array}$ \\
\hline $10 \mu \mathrm{l}$ anti-Rub antibody in PBS buffer & $11.3+/-4.0$ \\
\hline $4 \mathrm{mg}$ GM1 micelles $+10 \mu \mathrm{l}$ anti-Rub antibody in PBS buffer & $11.1+/-4.2$ \\
\hline $4 \mathrm{mg}$ GM1 micelles $+30 \mu \mathrm{l}$ anti-Rub antibody in PBS buffer & $33.3+/-6.1$ \\
\hline
\end{tabular}

Table 3: Flow cytometry analysis of GM1 micelles pre-incubated with a three-color monoclonal antibody combination (OptiClone).

\begin{tabular}{|c|c|c|c|c|c|c|}
\hline Monoclonal antibody & $\mathbf{C D}^{4+}$ & $\mathbf{C D}^{4+}$ & $\mathbf{C D}^{8+}$ & $\mathbf{C D}^{8+}$ & $\mathbf{C D}^{3+}$ & $\mathbf{C D}^{3+}$ \\
\hline Sample & $\begin{array}{c}\text { Counts/ } \\
\mathbf{m m}^{3}\end{array}$ & $\%$ & $\begin{array}{c}\text { Counts/ } \\
\mathbf{m m}^{3}\end{array}$ & $\%$ & $\begin{array}{c}\text { Counts/ } \\
\mathbf{m m}^{3}\end{array}$ & $\%$ \\
\hline $\begin{array}{c}\text { Control (+): 5 ul of Three-color } \\
\text { Antibodies standards in Vf: } 50 \\
\text { ul PBS buffer }\end{array}$ & 2326 & 56 & 1039 & 25 & 3698 & 89 \\
\hline $\begin{array}{c}\text { GM } \text { micelles (1 mg) +5ul } \\
\text { of Three-color Antibodies } \\
\text { standards in Vf: 50 ul PBS } \\
\text { buffer }\end{array}$ & 2410 & 58 & 977 & 23.5 & 3694 & 89 \\
\hline $\begin{array}{c}\text { Control (-): GM1 micelles (1 } \\
\text { mg) +5 ul (Anti-Rabbit-FITC) } \\
\text { Antibody in Vf: } 50 \text { ul PBS } \\
\text { buffer }\end{array}$ & 2 & 0 & 3 & 0 & 1 & 0 \\
\hline
\end{tabular}


Citation: Garro AG, Alasino RV, Leonhard V, Heredia V, Beltramo DM (2019) Antibodies can be Spontaneously Loaded onto Monosialoganglioside Micelles Containing Oncological Drugs. J Nanomed Nanotechnol 10: 532. doi: 10.35248/2157-7439.19.10.532

Page 7 of 10

Table 4: Semi-quantitative colorimetric determination by absorbance at $490 \mathrm{~nm}$ of antibodies attached to the micelles against surface receptors expressed on in vitro cell lines HeLa, H1299, Hep-2 and B16. Anti-FR IgG: anti-folate receptor antibody; anti-CD44 IgG: anti-hyaluronic acid receptor antibody and anti-LDLR IgG: low density lipoprotein receptor antibody.

\begin{tabular}{|c|c|c|c|c|c|c|c|c|c|c|c|c|}
\hline \multirow{2}{*}{ 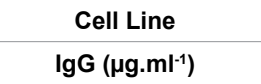 } & \multicolumn{4}{|c|}{ Hep-2 } & \multicolumn{4}{|c|}{ B16 } & \multicolumn{4}{|c|}{ H1299 } \\
\hline & 5 & 10 & 15 & 20 & 5 & 10 & 15 & 20 & 5 & 10 & 15 & 20 \\
\hline \multicolumn{13}{|l|}{ Sample } \\
\hline Anti-FR IgG & 0.1 & 0.08 & 0.13 & 0.12 & 0.34 & 0.53 & 0.51 & 0.54 & 0.3 & 0.09 & 0.14 & 0.11 \\
\hline GM1/Anti-FR IgG & 0.06 & 0.09 & 0.1 & 0.11 & 0.31 & 0.55 & 0.56 & 0.52 & 0.11 & 0.07 & 0.12 & 0.09 \\
\hline Anti-LDLR IgG & 0.36 & 0.59 & 0.67 & 0.71 & 0.19 & 0.26 & 0.36 & 0.37 & 0.08 & 0.12 & 0.11 & 0.16 \\
\hline GM1/Anti-LDLR IgG & 0.33 & 0.6 & 0.7 & 0.74 & 0.16 & 0.25 & 0.39 & 0.41 & 0.08 & 0.09 & 0.1 & 0.12 \\
\hline Anti-CD44 IgG & 0.09 & 0.11 & 0.13 & 0.1 & 0.13 & 0.17 & 0.14 & 0.17 & 0.33 & 0.46 & 0.49 & 0.51 \\
\hline GM1/Anti-CD44 IgG & 0.05 & 0.08 & 0.11 & 0.11 & 0.09 & 0.15 & 0.15 & 0.18 & 0.3 & 0.44 & 0.51 & 0.54 \\
\hline $\begin{array}{l}\text { Total human IgG } \\
\text { antibodies }\end{array}$ & & 0.13 & & 0.11 & & 0.09 & & 0.13 & & 0.09 & & 0.11 \\
\hline $\begin{array}{l}\text { GM1/Total human IgG } \\
\text { antibodies }\end{array}$ & & 0.09 & & 0.09 & & 0.1 & & 0.11 & & 0.06 & & 0.09 \\
\hline
\end{tabular}

Table 5: Loading of Ptx into GM1-lgG micelles at different GM1-lgG weight ratios or into free GM1 micelles and then incubated with IgG at different GM1/lgG weight ratios The loading of Ptx into GM1 and GM1-IgG were done at $20^{\circ} \mathrm{C}$ for $30 \mathrm{~min}$, and the loading of IgG into GM1 or GM1-Ptx were done at $20^{\circ} \mathrm{C}$ for $1 \mathrm{~h}$ at pH 4.5 .

\begin{tabular}{|c|c|c|}
\hline & & \multicolumn{2}{|c|}{ Ptx Soluble (\%) } \\
\hline Weight ratios & GM1-IgG-Ptx & GM1-Ptx-IgG \\
\hline $15 / 1$ & 48 & 98 \\
\hline $10 / 1$ & 42 & 98 \\
\hline $8 / 1$ & 16 & 96 \\
\hline $4 / 1$ & 6 & 99 \\
\hline $2 / 1$ & 3 & 97 \\
\hline
\end{tabular}

that binds to GM1-Doxo micelle. When GM1-Doxo complex is obtained at molar ratio of 5/1 GM1-Doxo, the maximun capability of GM1 to load Doxo [13], the percentage of IgG binding falls almost completely (data not shown). These results suggest a competitive relationship between Doxo and IgG by common sites within the micellar structure.

\section{Studies of in vitro release and cytotoxicity activity of paclitaxel and doxorubicine loaded in GM1-IgG-drug complexes}

Finally, we evaluate the cytotoxic effect of Ptx or Doxo present in this GM1-drug-IgG complexes and compare with previously report of GM1-Ptx [13], to determine if the presence of the immunoglobulin in the micelles produces any change in the biological activity in vitro of the loaded drug.

Paclitaxel was incorporated in two samples of GM1 at GM1-Ptx molar ratio 10:1, the maximun binding capability. Then, one sample was incubated with IgG (anti-CD44 IgG) in a ratio 4:1 to saturate GM1Ptx to obtain GM1-Ptx-IgG complexes, and the citotxic effect of Ptx was evaluated on the H1299 cell line using GM1- Ptx -IgG inespecific and GM1-Ptx as controls. The results showed that the cytotoxic activity of Ptx were similar in all cases (data not shown). Control of vehicle, GM1IgG (anti-CD44), did not show toxic effects on the cellular monolayers (data not shown). Similar results were obtained when assays were performed with other specific antibodies in their respective susceptible cell lines (see materials and methods).

In the same way, assays performed with Doxo loaded on the different GM1-Doxo- IgGspecific formulations did not reveal significant differences in cell viability with respect to GM1- Doxo$\mathrm{IgG}_{\text {inespecific }}$ and GM1-Doxo. These results suggest that the presence of the antibody in the micellar structure does not modify the release and uptake of the drugs.
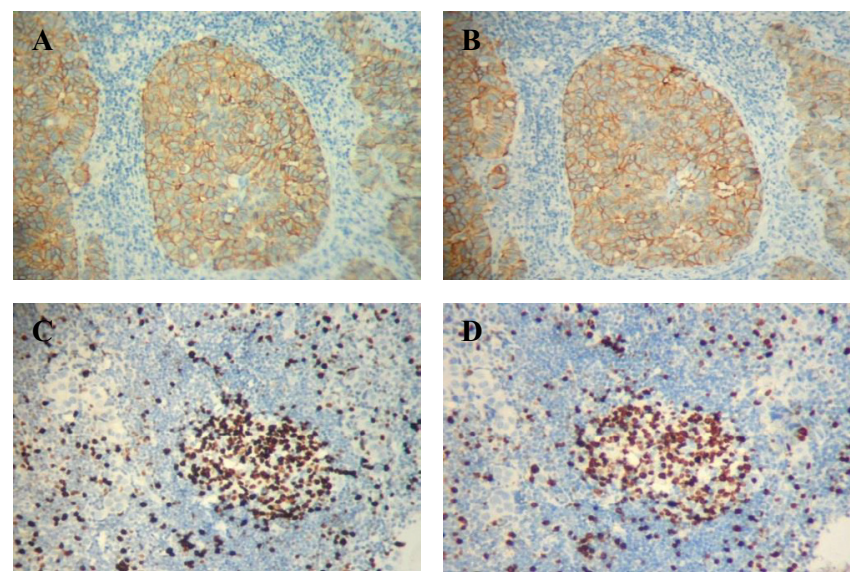

Figure 5: Immunohistochemistry images of human tumor tissue sections incubated with anti-Her2/neu monoclonal primary Antibody (A), GM1 micelles coated with anti-Her2/neu monoclonal primary Antibody (B), anti-Ki-67 monoclonal primary Antibody (C) and GM1 micelles coated with anti-Ki-67 monoclonal primary Antibody (D).

\section{Discussion}

The use of antibodies against selectively expressed antigens on the surface of cancer cells is a therapeutic strategy widely studied not only as directed immunotherapy but also for its potential to selectively target drugs or drug delivery systems [24,25].

In a previous report $[12,13]$ we demonstrate that GM1 is able to load and release hydrophobic and hydrophilic oncological drugs in GM1-Drug complex. When this complex is incubated in presence of whole serum, there is only one protein, albumin, that spontaneously 
bind in a non-covalent form to GM1-Drug-Albumin complex. In this report we describe a new procedure to load IgG into GM1 micelles to form GM1-IgG complex that under specific conditions also retain the capability of load drugs to generate the GM1-Drug-IgG.

This complex could be considered a delivery system for an immune-chemotherapeutic capable of combining the properties of drugs transported in the micelles [26,27] with the specific recognition capacity of the antibodies.

We demonstrate that the load of IgG into GM1 micelles was controlled by two principal factors such as the $\mathrm{pH}$ and temperature, conditions that affect IgG and GM1 structures to allow a non-covalent interaction,

Changes in the $\mathrm{pH}$ from $\mathrm{pH} 7,4$ to $\mathrm{pH} 4.5$ produce significative increase in the interaction between GM1 micelles with IgG. This favorable interaction at $\mathrm{pH} 4.5$ seems not related to changes in GM1 micelles since no modification were reported by GM1 but related to the conformational state that suffer IgG known as "reversible conformational denaturation", and especially for Fc fragment $[15,16]$. In this condition, there is a partial exposure of their hydrophobic residues of $F_{c}$ involved in the interaction with micelles. On the other hand, the fact that addition of high salt concentrations in the incubation media, does not prevent interaction between micelles and antibodies reinforce the idea of the hydrophobic nature of the interaction.

Instead, the temperature was a critical factor for both molecules. When IgG and GM1 micelles were co-incubated from 4 to $45^{\circ} \mathrm{C}$, and moreover when free GM1 micelles were pre-heated at $55-60^{\circ} \mathrm{C}$, there is a clear increase in the capability of GM1 to load IgG.

The temperature shows two phases, until $45^{\circ} \mathrm{C}$ both IgG and GM1 micelles seems to be modified to improve the interaction, but this temperature was the limit of IgG before an irreversible denaturation. However the thermal treatment at $55-60^{\circ} \mathrm{C}$ of free GM1 micelles before to incubation with antibodies produces the maximun GM1IgG complex. In this case the effect is only for the conformational changes in the surface of GM1 micelles due to the dehydration of the polar groups of the ganglioside molecule that produce an increase of the hydrophobicity that undergoes the micellar structure at that temperature $[20,21]$. Under this experimental condition permit to avoids exposure of immunoglobulins to high temperatures, which compromise their functionality. After select the optimal interaction condition to obtain the more stable GM1-IgG complexes, $\mathrm{pH} 4,5$ and heating GM1 micelles $55-60^{\circ} \mathrm{C}$, the maximun ratio GM1-IgG was reached to $4 / 1(\mathrm{w} / \mathrm{w})$. Moreover under this condition the spontaneously binding of albumin to GM1 micelles mentioned above, does not occurs.

The characterization of the size and morphology of this GM1-IgG complexes by DLS and TEM showed a size considerably higher than that of free GM1 micelles, $25.1 \mathrm{~nm}$ and $11.9 \mathrm{~nm}$ respectively but with a similar rounded morphology, suggesting that IgG do not affect the geometry of complex. It is interesting to remark the results obtained with pepsin, a well-known protease that cleaves immunoglobulins in $\mathrm{Fc}$ and Fab fragments, the enzyme causes the release of Fab fragment in contact with free IgG, however, when exposed under similar conditions to the IgG bound to GM1-IgG complex, pepsin shows little activity on the immunoglobulin (Figure 4). Although it cannot be ruled out that this behavior respond to steric impediments that prevent the enzyme from accessing its target site, this fact may also be a consequence of the spatial location of the immunoglobulin in the micelle, with its Fc region protected inside.
On the other hand, we also evaluate whether antibodies retain their antigenic recognition ability after its physical association to GM1 micelles. The assays demonstrate that different specific monoclonal antibodies loaded onto GM1 micelles were able to recognize fragments of soluble antigens, or located in the cell surface such receptors or intracellular antigen used for histochemical. This study suggest that this GM1-IgG complex do not show any sterical impediment of IgG to react with different antigen. Both results are in agreement with the possibility that under this specific condition the insertion of IgG into GM1 micelles occurs through Fc leaving the biological active Fab fragment.

The results clearly demonstrate that GM1-IgG complexes are able to overcome two of the main drawbacks of using a non-covalent binding method, one referring to the displacement of antibodies by plasma proteins and the other to the loss of functionality due to a bad orientation of antibodies during binding to the micelle-

It is well known that antibodies are therapeutically useful molecules by themselves, capable of producing direct pharmacological effects, such as blocking the interaction of a receptor with a ligand, interfering with a multimerization process or activating receptor internalization or apoptosis of target cells with numerous intermediate cell modulation options $[9,28]$. The incorporation of antibodies into micellar structure could be considered as a strategy for improvement in the pharmacokinetic and biodistribution properties of the antibodies, which often do not achieve the effectiveness sought by low plasma halflife or because they do not reach the tumor tissues; variables in which GM1 micelles could offer substantial advantages such as crossing the blood-brain barrier and entering the brain [29]. This encapsulation of IgG into micelles of GM1 also could be used for improving the biodistribution by facilitating selective tumor accumulation through enhanced permeability and retention (EPR) effect [28-30].

On the other hand previously reports by owner and others shows that GM1 micelles were able to load and release oncological drugs such as Paclitaxel and Doxorubicine and moreover that the complex were able to cross brain blood barrier [12,13,29]. In these experimental conditions we also shown that GM1-IgG complex retain the capability of load drugs such as Ptx or Doxo, although it is necessary to follow a specific sequence in order to obtain stable GM1-IgG -drug complexes. For Paclitaxel, it must be incorporated into micelles before incubation with the antibodies, because the presence of $\operatorname{IgG}$ in the micellar structure prevents its incorporation. Following the order mentioned, Ptx can be loaded up to a GM1/Ptx molar ratio of 5/1 that represent is the maximum Ptx loaded capability in GM1 micelles alone, then IgG also can be loaded also at maximun weight/weight ratio capability GM1-IgG 4:1. These results suggest that antibodies occupy more external domains in the micelles structure which are critical for Ptx insertion.

With Doxo, its incorporation depends on the amount of IgG bound to the micelle and vice versa. At GM1-IgG 4/1 ratios (w/w) complex the amount of Doxo loaded is lower than $25 \%$ as was observed for GM1 alones, and when the amount of Doxo previously loaded onto GM1 micelles increase, the encapsulation IgG decrease until to be not detectable. This result suggesting that both molecules, IgG and Doxo, share common binding domains in the micelles.

The results of in vitro cytotoxicity assays revealed that drugs into GM1- ${ }_{\text {specific }}$ IgG micelles show a similar biological effect to drugs loaded

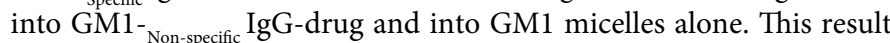
demonstrates first, that the presence of the immunoglobulin in the 
Citation: Garro AG, Alasino RV, Leonhard V, Heredia V, Beltramo DM (2019) Antibodies can be Spontaneously Loaded onto Monosialoganglioside Micelles Containing Oncological Drugs. J Nanomed Nanotechnol 10: 532. doi: 10.35248/2157-7439.19.10.532

Page 9 of 10

micellar structure does not affect the release of the drugs contained therein. On the other hand, was unexpected the similar toxicity observed for GM1-Drug loaded with specific or unspecific IgG. Although some kind of difference could be expected, mainly in the kinetics of the activity so, there are many basic points between the in vitro and the in vivo system that can be considered in the analysis. First, the use of antibodies bound either a nanocarrier or one drug itself is based on the potential selectivity of the immunoglobulin against the different cell types in the organism, which is a very different for the in vitro condition, where the assays are performed with pure cellular monolayers of a single cell type in each case. Likewise, there is a great variety of dynamic and structural factors that are not reflected in the in vitro model. All this, added to the high efficiency of the micellar system itself for the in vitro transport and drug delivery. The rapid fusion or interaction of GM1 micelles with cells may be masking antibody participation, together with the low internalization capacity of immunoglobulins.

Most monoclonal antibodies were developed to fulfill effector immune functions and not to internalize. In an active targeting system, the antibodies are mainly used as "hooks" to facilitate the binding of the nanotransporter to the cell expressing the ligands, increasing retention at the site of interest.

This report opens the possibility to incorporation of antibodies with different targets of action in a same nanocarrier that contain oncological drugs as a new alternative for different therapeutic purposes.

\section{Conclusions}

The results demonstrate the ability of GM1 micelles to interact and incorporate IgG into their structure, maintaining their ability to charge drugs with different physicochemical characteristics. In summary, the results described show that:

- IgG antibodies can be incorporated into GM1 micelles in a stable, simple and efficient manner.

- Incorporated antibody maintains its biological activity of recognition of its specific antigen.

- GM1 micelles modified with IgG maintain their capacity to carry drugs like Ptx and Doxo, but their preparation requires following an appropriate order to obtain the maximum load capacity.

- The GM1-IgG -drug model can be proposed as a dual or multifunctional system, in which the action of several antibodies is combined with the transport of drugs with the potential to be used for different therapeutic purposes.

\section{Acknowledgement}

This work was supported by Centro de Excelencia en Productos Córdoba, Argentina, (CEPROCOR) and Consejo Nacional de Investigaciones Científicas Técnicas de Argentina (CONICET).

\section{References}

1. Kocbek P, Obermajer N, Cegnar M, Kos J, Kristl J (2007) Targeting cancer cells using PLGA nanoparticles surface modified with monoclonal antibody. J Control Release 120: 18-26.

2. Sun B, Ranganathan B, Feng SS (2008) Multifunctional poly (D,L-lactideco-glycolide)/montmorillonite (PLGA/MMT) nanoparticles decorated by Trastuzumab for targeted chemotherapy of breast cancer. Biomaterials 29: 475-486.

3. Yousefpour P, Atyabi F, Vasheghani-Farahani E, Movahedi AA, Dinarvand $R$ (2011) Targeted delivery of doxorubicin-utilizing chitosan nanoparticles surface-functionalizedwith anti-Her2 trastuzumab, Int J Nanomedicine 6 : 1977-1990.

4. Yu, MK, Park J, Jon S (2012) Targeting strategies for multifunctional nanoparticles in cancer imaging and therapy. Theranostics 2: 3-44.

5. Fahmy TM, Fong PM, Goyal A (2005) Targeted for drug delivery. Mater Today 8: 18-26.

6. Torchillin VP, Lukyanov AN, Gao Z, Papahadjopoulos-Sternberg B (2003) Immunomicelles: Targeted pharmaceutical carriers for poorly soluble drugs. Proc Natl Acad Sci USA 100: 6039-6044.

7. Ortega-Vinuesa JL, Hidalgo-Álvarez R, de las Nieves FJ, Davey CL, Newman DJ, et al. (1998) Characterization of Immunoglobulin G Bound to Latex Particles Using Surface Plasmon Resonance and Electrophoretic Mobility. J Colloid Interface Sci 204: 300-311.

8. Ruoslahti E, Bhatia SN, Sailor MJ (2010) Targeting of drugs and nanoparticles to tumors. J Cell Biol 188: 759-768.

9. Sharkey RM, Goldenberg DM (2006) Targeted therapy of cancer: new prospects for antibodies and immunoconjugates. CA Cancer J Clin 56: 226243

10. Kim JH, Yoon JY (2002) Protein Adsorption on Polymer Particles. Encyclopedia of Surface and Colloid Science.

11. Balthasar S, Michaelisa K, Dinauerb N, von Briesen H, Kreuter J, et al. (2005) Preparation and characterisation of antibody modified gelatin nanoparticles as drug carrier system for uptake in lymphocytes. Biomaterials 26: 2723 2732 .

12. Leonhard V, Alasino RV, Bianco ID, Garro AG, Heredia V, et al. (2012) Selfassembled micelles of monosialogangliosides as nano delivery vehicles for taxanes. J Control Release. 162: 619-627.

13. Leonhard V, Alasino RV, Bianco ID, Garro AG, Heredia V, et al. (2015) Biochemical characterization of the interactions between doxorubicin and lipidic GM1 micelles with or without paclitaxel loading. Int J Nanomedicine 10: 3377-3388.

14. Hirai M, Takizawa T (1998) Intensive extrusion and occlusion of water in ganglioside micelles with thermal reversibility. Biophys J 74: 3010-3014.

15. Vermeer AWP, Norde W (2000) The thermal stability of immunoglobulin: unfolding and aggregation of a multi-domain protein. Biophys J 78: 394-404

16. Vermeer AWP, Norde W, Amerogen A (2000) The Unfolding/Denaturation of Immunogammaglobulin of Isotype $2 \mathrm{~b}$ and Its Fab and Fc Fragments. Biophys J 79: $2150-2154$

17. Leonhard V, Alasino RV, Bianco ID, Beltramo DM (2013) Selective Binding of Albumin to GM1 Ganglioside Micelles Containing Paclitaxel. J Nanomed Nanotechol 4: 159

18. Lowry OH, Rosebrough NJ, Farr AL, Randall RJ (1951) Protein measurement with the Folin phenol reagent. J Biol Chem 193: 265.

19. Abraham SA, Edwards K, Karlsson G, Macintosh S, Mayer LD, et al. (2002) Formation of transition metal-doxorubicin complexes inside liposomes. Biochim Biophys Acta 1565: 41-54

20. Cantú L, Corti M, Del Favero E (1999) Thermal hysteresis in ganglioside micelles investigated by differential scanning calorimetry and light-scattering Langmuir 15: 4975-4980.

21. Orthaber D, Glatter O (1998) Time and temperature dependent aggregation behavior of the ganglioside GM1 in aqueous solution. Chem Phys Lipids 92 53-62.

22. Tomasi M, Roda LG, Ausiello C, D'Agnolo G, Venerando B (1980) Interaction of GM1 ganglioside with bovine serum albumin: formation and isolation of multiple complexes. Eur J Biochem 111: 315-324.

23. Venerando B, Roberti S, Sonnino S, Fiorilli A, Tettamanti G (1982) Interactions of ganglioside GM1 with human and fetal calf sera. Formation of gangliosideserum albumin complexes. Biochim Biophys Acta 22: 18-26.

24. Scott AM, Wolchok, Old LJ (2012) Antibody therapy of cancer. Nat Rev Cancer 12: 278-287.

25. Dan N, Setua S, Kashyap VK, Khan S, Jaggi M, et al. (2013) Antibody Drug Conjugates as Cancer Therapeutics. Antibodies 2: 113-129. 
Citation: Garro AG, Alasino RV, Leonhard V, Heredia V, Beltramo DM (2019) Antibodies can be Spontaneously Loaded onto Monosialoganglioside Micelles Containing Oncological Drugs. J Nanomed Nanotechnol 10: 532. doi: 10.35248/2157-7439.19.10.532

Page 10 of 10

26. Maeda $H$ (2001) The enhanced permeability and retention (EPR) effect in tumor vasculature: the key role of tumor-selective macromolecular drug targeting. Adv Enzyme Regul 41: 189-207.

27. Bazak R, Houri M, Achy SE, Hussein W, Refaat T (2014) Passive targeting of nanoparticles to cancer: A comprehensive review of the literature. Mol Clin Oncol 2: 904-908.

28. Weiner LM, Surana R, Wang S (2010) Antibodies and cancer therapy: versatile platforms for cancer immunotherapy. Nat Rev Immunol 10: 317-327.
29. Zou D, Wang W, Lei D, Yin Y, Ren P, et al. (2017) Penetration of blood-brain barrier and antitumor activity and nerve repair in glioma by doxorubicinloaded monosialoganglioside micelles system. Int J Nanomedicine 12: 4879 4889.

30. Watanabe R, Choyke PL, Kobayashi H (2014) Improving Conventiona Enhanced Permeability and Retention (EPR) Effects. What Is the Appropriate Target? Theranostics 4: 81-89. 